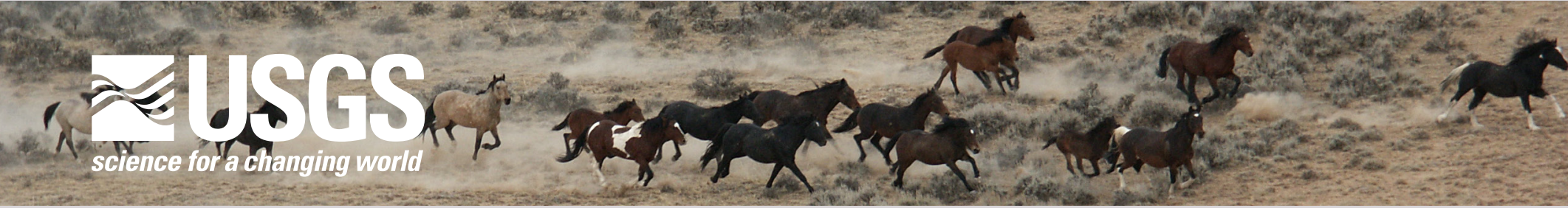

\title{
FORT COLLINS SCIENCE CENTER Ecosystem Dynamics Branch
}

\section{Capabilities}

Complex natural resource issues require understanding a web of interactions among ecosystem components that are (1) interdisciplinary, encompassing physical, chemical, and biological processes; (2) spatially complex, involving movements of animals, water, and airborne materials across a range of landscapes and jurisdictions; and (3) temporally complex, occurring over days, weeks, or years, sometimes involving response lags to alteration or exhibiting large natural variation. Scientists in the Ecosystem Dynamics Branch of the U.S. Geological Survey, Fort Collins Science Center (FORT), investigate a diversity of these complex natural resource questions at the landscape and systems levels, with a focus on the following areas:

\section{- Energy and Land Use}

Applied research and integrated regional assessments emphasize spatially explicit analyses of ecosystem components affected by energy development and land-use change in the western United States. Topics include sagebrush-steppe ecology; sagebrush habitat assessments; the effects of human activities (including energy development, transportation, and recreation) on habitat health and wildlife behavior; habitat fragmentation and disrupted migration corridors; and tool development for managers and decision makers.

\section{- Climate Change and Long-term Integrated Assessments}

Research on Federal trust lands, especially in the mountains of western national parks and forests, addresses long-term ecosystem dynamics associated with climate change. Studies include ecosystem biogeochemistry, atmospheric deposition, forest dieback, and assessment of forest biomes ranging from the Arctic to

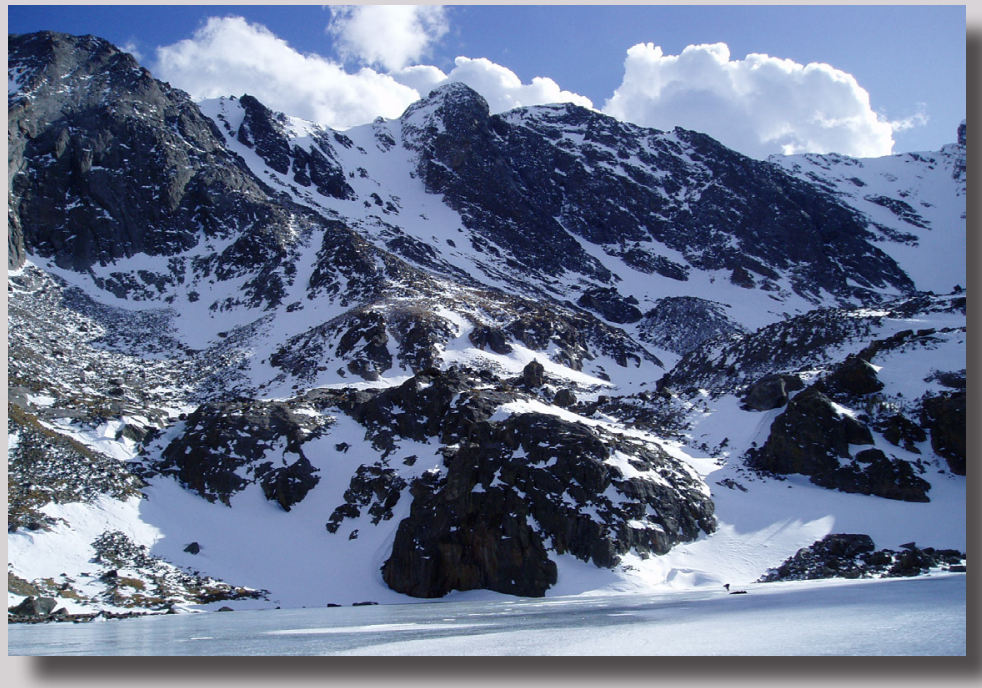

Sky Pond in Loch Vale watershed, Rocky Mountain National Park. Photo: Jill Baron, USGS.

the desert Southwest. FORT scientists are collaborating with researchers from around the world to describe and document global patterns of climate-induced forest dieback.

\section{- Herbivore-Ecosystem Interactions}

Data from these studies help inform ungulate management decisions on public lands, typically in large, jurisdictionally complex landscapes. Recent work involves investigations on the impacts of herd size and movements of elk, bison, and wild horses on various ecosystem components. Specifically, scientific efforts include (1) quantifying interactions among carnivores, herbivores, plants, and soils; (2) determining the effects of ungulate herbivory on ecosystem processes and vegetation communities; (3) testing survey techniques for more accurate population estimates; and (4) evaluating contraceptive methods for managing wild horse populations. 


\section{- Fire and Post-Fire Restoration}

This research examines the effects of fire on plant and animal communities at various spatial and temporal scales. Using interdisciplinary approaches, scientists investigate post-fire rehabilitation (including community education), interactions between post-fire biotic (plant establishment, including invasive species) and abiotic (runoff and erosion) processes, and public responses during fire emergency situations.

\section{- Environmental Flows and River Restoration}

Anthropogenic alteration of watersheds impacts the quantity and quality of surface and ground waters. Land-use changes and development have long-lasting and often permanent adverse effects on the plants and animals that share these environments with human populations. Current research in regulated and unregulated river basins integrates hydrology and hydraulics, fluvial geomorphology, river and riparian ecology, and aquatic habitat modeling to explain and predict patterns and variation in ecological responses to perturbations. Research addresses management issues such as water supply, restoration of aquatic and riparian habitats, and the effects of instream flow on native riparian vegetation, invasive plants, and endangered wildlife.

\section{Selected Projects}

\section{Energy and Land-Use Research and Technical Assistance}

Exploration and development of domestic oil and gas resources have become a national priority, yet our understanding of the direct and indirect effects of energy development on surrounding ecosystems remains limited. This poses a challenge for natural resource managers, who are balancing priorities that include maintaining healthy rangelands and wildlife habitats while providing for resource development and multiple public uses. Scientists at FORT and several other USGS science centers, along

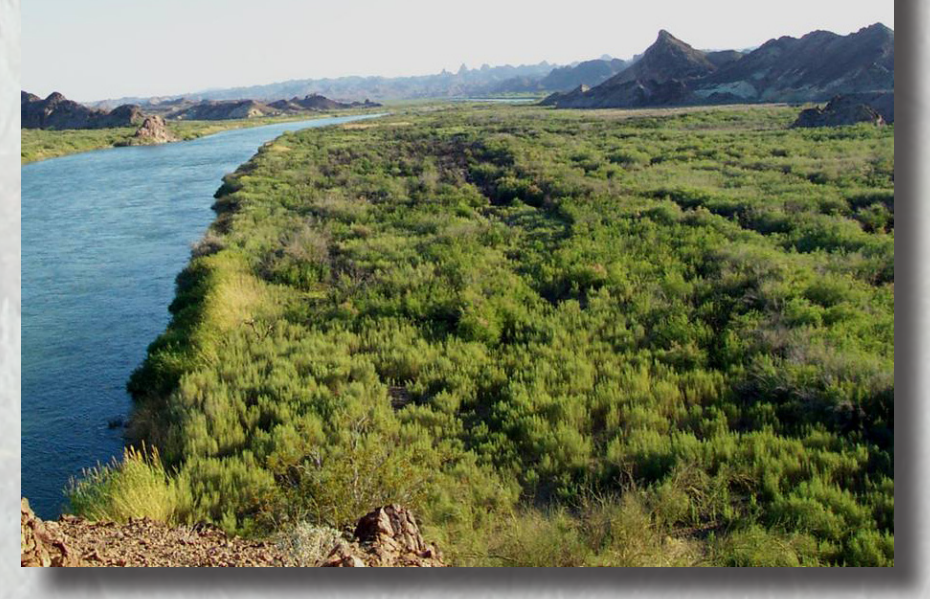

Tamarisk-dominated vegetation along the lower Colorado River, California-Arizona. Photo: Pat Shafroth, USGS. with Federal, State, and local partners, are jointly conducting interdisciplinary research focusing on these issues at a regional landscape level in the western United States. This interdisciplinary work contributes directly to the Wyoming Landscape Conservation Initiative (WLCI), a longterm, landscape-scale science collaboration to ensure full consideration and adaptive management of Wyoming's wildlife and habitats in the face of increasing land-use pressures. Scientists are investigating diverse energy and land-use issues by using a multidisciplinary approach to assess sagebrush habitat condition; employ targeted research and monitoring plans; identify and evaluate the ecological impacts of fire, grazing, roads, and energy development on sagebrush ecosystems and species; refine scientific understanding of sage-grouse population dynamics and genetics; and develop predictive models and maps that address management priorities.

\section{Western Mountain Ecosystem Responses to Climate Change}

FORT is participating in the Western Mountain Initiative, a cooperative effort to understand and predict the sensitivities, thresholds, resistance, and resilience of western mountain ecosystems to climatic variability and change. FORT scientists helped develop vulnerability indices of select mountain regions in Colorado, New Mexico, Montana, Washington, and California to current climate variability and future climate changes. They also are (1) continuing long-term ecological research and monitoring of the Loch Vale watershed in Rocky Mountain National Park, Colo., and Bandelier National Monument, N.M.; (2) clarifying centennial- to millennial-length shifts in past vegetation and fire regimes; (3) elucidating responses of fire to short-term climatic variation; (4) determining long- and short-term climatic controls of tree mortality, including thresholds for dieback; (5) documenting rapid and extensive climate-induced vegetation mortality, including global patterns of massive forest dieback; and (6) determining the effects of climatic variability, fire, and land use on watershed runoff and erosion processes. A FORT scientist also was lead author for the chapter on national parks in Preliminary Review of Adaptation Options for Climate-Sensitive Ecosystems and Resources, a report to Congress by the U.S. Climate Change Science Program and Subcommittee on Global Change Research, and a national collaboration among scientists from numerous agencies, universities, and nonprofit organizations.

\section{Riparian Exotic Species}

In the arid and semi-arid interior of western North America, riparian cottonwood, willow, and other native species are being replaced by exotic shrubs and trees. The most abundant of these, saltcedar (or tamarisk), now covers about 500,000 hectares and is the dominant riparian woody species in much of the southwestern United States. Russian olive and Siberian elm are other invasive species prevalent in the West. These great changes in species composition of riparian woody plants have been associated with loss of plant diversity, degradation of habitat for 


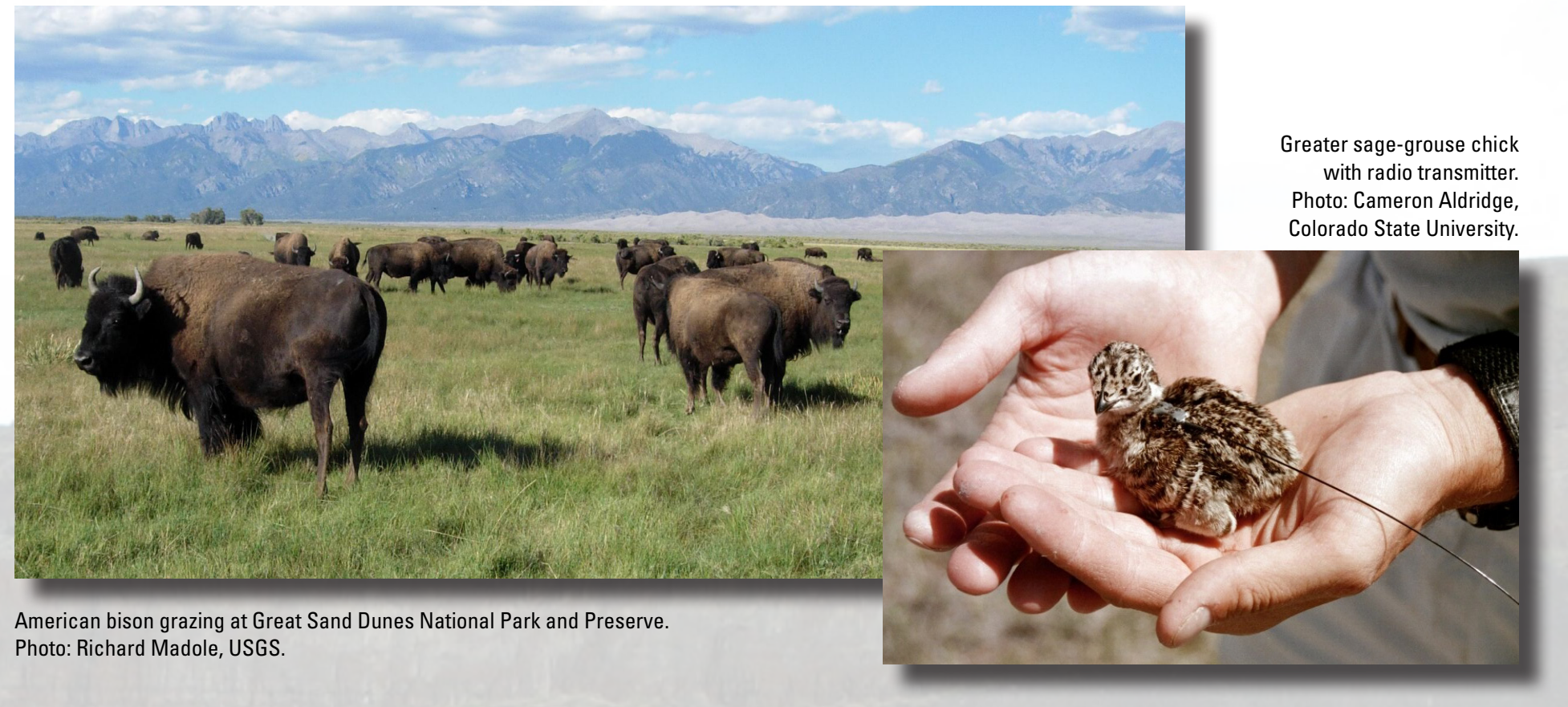

vertebrate animals, decreased channel conveyance, increased water loss from evapotranspiration, and loss of aesthetic and recreational opportunities. Scientists are examining how environmental factors, including climate change, latitude, livestock grazing, substrate composition, flood regimes, and the upstream presence of dams influence the susceptibility of a river to invasion, especially by saltcedar and Russian olive. This information is being provided to land managers who need to know which systems are most susceptible to invasion by exotics and which are most likely to respond positively to restoration efforts.

\section{Elk and Bison Grazing Ecology in Great Sand Dunes National Park and Preserve}

FORT scientists are conducting studies on bison and elk in the Great Sand Dunes National Park and Preserve to determine population status and movements, the effects of herbivory, and suitable habitat and population potential in the park and surrounding lands. Scientists will use these data to develop an elk and bison grazing model that includes grazing as a significant natural ecological process and incorporates protection of sensitive nativeplant communities. Scientists are applying study results to development of a predictive management-planning model that will make predictions based on several management scenarios. These tools will directly support park managers in developing and evaluating management alternatives for elk and bison.

\section{River and River Basin Modeling}

Resource management agencies continually face the need to reach defensible conclusions and prepare documents describing the processes and reasoning behind management decisions. The complexity of water resource management requires interdisciplinary conversations about such diverse issues as physical parameters, habitat, water flow, chemistry, biology, and social needs. Decision support systems provide interactive, flexible, and adaptable computer-based information systems for quantifying tradeoffs and multiple resource impacts related to changes in water management. FORT scientists are developing customized model components for use in interactive decision-support systems that evaluate changes in hydrologic, hydraulic, and instream flow values.

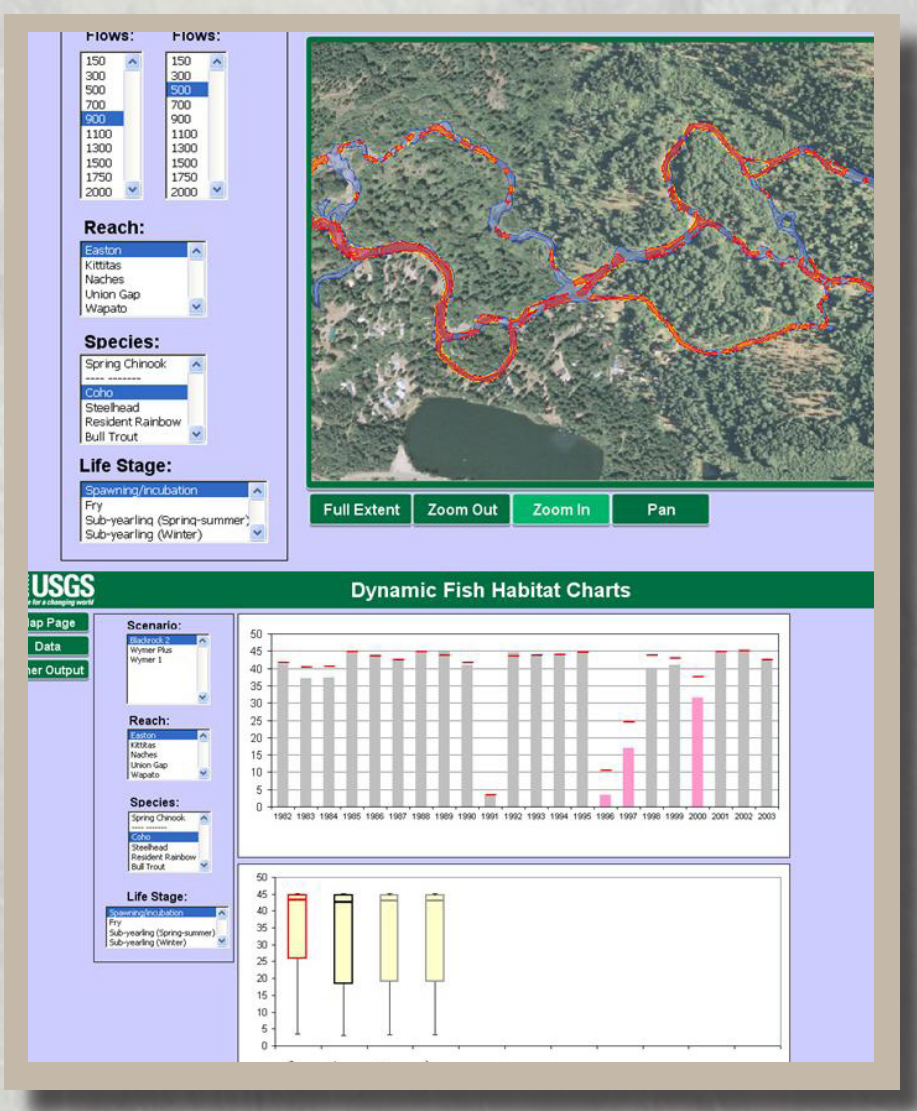

Yakima River geospatial information system. Example shows spawning/ incubation habitat persistence map for Coho salmon (top) and associated habitat time-series analysis (bottom). Images: Ken Bovee, USGS. 
